\title{
Patrimônio e paisagem cultural: reflexões sobre a preservação das paisagens urbanas contemporâneas
}

Cristiane Maria Magalhães

\section{Resumo}

A inscrição da cidade do Rio de Janeiro na Lista de Patrimônio da Humanidade, na categoria Paisagem Cultural, durante a $36^{a}$ sessão do Comitê do Patrimônio Mundial, ocorrida no dia $1^{\circ}$ de Julho de 2012, fomentou o tema em pauta nas discussões patrimoniais da última década. O intuito deste texto é realizar uma reflexão a respeito da prática da preservação das paisagens culturais brasileiras, no âmbito do órgão federal, atual IPHAN, ao longo do século XX. Entre a década de 1930 e 2000 houve uma mudança significativa no tratamento ao tema paisagem cultural. Quais seriam, nos dias atuais, os critérios para a eleição de uma paisagem cultural representativa dessas identidades brasileiras? É a inquietação que guia a discussão proposta.

Palavras-chave: Patrimônio. Paisagem cultural. Salvaguarda.

Heritage and cultural landscape: reflections about the preservation of contemporary urban landscapes

\section{Abstract}

The inscription of the city of Rio de Janeiro in the List of World Heritage in the category Cultural Landscape in the 36th Session of the World Heritage Committee, occurred on 1 July 2012, promoted the theme on the agenda in discussions heritage of the past decade. The purpose of this paper is to develop a reflection on the practice of preservation of cultural landscapes in Brazil, under the federal agency, IPHAN, throughout the twentieth century. Between the 1930 and 2000, there was a significant change in the treatment to the cultural landscape subject. What is the criterion to the election of a cultural landscape representative of the Brazilian identities? It is the question that guide the discussion proposed.

Key-words: Heritage. Cultural landscape. Protection.

\section{Introdução}


Na cidade alemã de Hildesheim, no estado da Baixa Saxônia, existe um exemplo interessante de como arquitetura e espécie vegetal vêm convivendo, há séculos, de forma harmoniosa. A cidade foi fundada como sede episcopal católica em 815. Entre as paredes da Catedral de Santa Maria, em Hildesheim, floresce uma exuberante roseira milenar, desafiando a estrutura da construção medieval. Esta história inusitada foi narrada na Revista de Horticultura $n^{\circ} 6$, de 1876 :

\footnotetext{
Uma roseira velha: Junto à Igreja de Hildesheim, Alemanha, existe uma roseira brava, plantada por ordem do Imperador Carlos Magno (742-814), se é certo o que pretende a tradição local; mas como a roseira sai de uma abertura feita de propósito na parede da igreja, parece verdade que ela já existia antes da edificação desta, que é antiguíssima. O tronco, da grossura do corpo de um homem, atravessa a parede, que tem 1,50 m de espessura, e divide-se em cinco galhos, cujas ramificações cobrem a parede, contra a qual são sustentadas por uma latada vertical de ferro, com sete metros de altura, por oito de comprimento, mandada fazer, como consta dos papéis da Igreja, pelo Bispo Hepilo, isto é, entre os anos de 1054 e 1099. Desde o século 13ㄹ, esta roseira é considerada como uma maravilha. (REVISTA de Horticultura. N. 6, de junho de 1876. p. 105)
}

A história da "rosa de mil anos" é envolvida em lendas como a descrita acima, além de outras. Numa rápida pesquisa pela internet, é possível visualizar imagens da enorme roseira (Tausendjähriger Rosenstock), que floresce no mês de maio, na Catedral de Santa Maria. A Catedral teria sido edificada por volta de 872 (UNESCO. Vídeo, s/d). A espécie é a Rosa Canina L. (Rosacea), conhecida popularmente como Rosa Silvestre, de cinco pétalas e coloração delicada entre o branco e o rosa. A roseira tem 15 metros de altura e é considerada como a mais antiga do mundo. Por causa deste exemplar e das lendas, as roseiras tornaram-se símbolo da cidade de Hildesheim. Nas sacadas das casas, ou espalhadas pelas ruas, belas roseiras oferecem um espetáculo de cores e odores, anualmente, durante o verão e a primavera.

A Catedral de Santa Maria e a Igreja de São Miguel de Hildesheim foram inscritas na Lista de Patrimônio Mundial da Humanidade, pela Unesco, na nona sessão de Paris, em 1985, como exemplos de igrejas românicas do Sacro Império Romano. Tanto a Catedral, quanto a roseira estão protegidas pelo mesmo instrumento de salvaguarda, apesar de o foco da inscrição ser a edificação medieval.

O par natureza e cultura, ou, para usar um termo mais recente, a paisagem cultural apresenta-se como um dos desafios da preservação patrimonial do século XXI. Nas 
cidades coexistem, muitas vezes, em ambientes distintos, os espaços reservados às estruturas arquitetônicas e aqueles destinados às praças, parques e jardins. Em lugares como museus, centros de memória, galerias de arte, conventos e monastérios, os jardins postam-se como o entorno imediato dessas edificações. Nestes casos, os jardins ocupam o seu lugar e função, criando um parâmetro artístico e estético, preparando o espírito dos visitantes que chegam, antes de entrar na edificação, e, após sair dela, mantendo a aura artística do lugar.

No Brasil, a questão das paisagens culturais urbanas, e de sua preservação como espaços simultâneos de natureza e de cultura, encontra-se em evidência. No dia primeiro de julho de 2012, na $36^{a}$ sessão do Comitê do Patrimônio Mundial, realizada em São Petersburgo, Rússia, foi aprovada a inscrição da cidade do Rio de Janeiro na Lista do Patrimônio Mundial, na categoria Paisagem Cultural, com o tema "Rio de Janeiro: Paisagens Cariocas entre a Montanha e o Mar".

A cidade do Rio de Janeiro tornou-se a primeira, ao redor do mundo, a ostentar o desejado título. De acordo com o Dossiê apresentado à Unesco:

O bem "Rio de Janeiro: Paisagens Cariocas entre a Montanha e o Mar" enquadra-se na tipologia de Paisagem Cultural e é integrado por 4 (quatro) componentes localizados desde a Zona Sul do Rio de Janeiro ao ponto oeste de Niterói, no Grande Rio, englobando o Maciço da Tijuca, caracterizado por encostas íngremes, grandes afloramentos rochosos, como o Corcovado, o Pão de Açúcar e o Morro do Pico, em grande parte cobertos por vegetação tropical, ora nativa ora proveniente de reflorestamento ou agenciamento, como no Jardim Botânico e nos parques públicos. Inclui ainda as áreas onde a paisagem da orla tem sido agenciada ao longo dos séculos, seja para erigir fortificações para a defesa da cidade, como na entrada da Baía de Guanabara com seus fortes históricos, seja para propiciar instalações de lazer para os residentes, como o Passeio Público, o Parque do Flamengo e a Praia de Copacabana. (IPHAN, Dossiê RJ, 2012)

Algumas das citadas paisagens cariocas constituídas entre a montanha e o mar foram criadas no final do século XVIII (Passeio Público) e durante os séculos XIX e XX, incidindo sobre elas remodelações ou revitalizações significativas, como foram os casos dos jardins, praças e parques públicos.

$\mathrm{Na}$ abertura do Dossiê apresentado à Unesco, considerou-se a definição de Paisagem Cultural para caracterizar a inscrição, aquela constante do art. 47 do Operational 
Guidelines for the Implementation of the World Heritage Convention. O artigo 47 afirma que paisagens culturais são bens culturais e representam as «obras conjugadas do homem e da natureza» referente ao artigo $1^{\circ}$ da Convenção [de 1972]. Elas ilustram a evolução da sociedade humana e a sua consolidação, ao longo do tempo, sob a influência das condicionantes físicas e/ou das possibilidades apresentadas pelo seu ambiente natural e das sucessivas forças sociais, econômicas e culturais, externas e internas.

O termo paisagem, tomado por diversos campos do conhecimento e da arte, é polissêmico e possui acepções variadas, e também se desdobra, nos dias atuais, nas problematizações do Patrimônio com a categoria de Paisagem Cultural. Para Paisagem Cultural, um dos denominadores comuns das definições para o Patrimônio é o seu entendimento como «obra conjugada do homem e da natureza».

Organizada pela Unesco, aconteceu, em 1972, a Conferência Geral da Organização das Nações Unidas para a Educação, Ciência e Cultura, reunida em Paris, quando foi instituída a Lista do Patrimônio da Humanidade, para inscrição de bens de valor excepcional ao redor do mundo. Poderiam ser inscritos nessa lista bens patrimoniais com critérios Culturais ou Naturais, distintamente.

Consideraram-se como Patrimônio Cultural, obras arquitetônicas, esculturas, pinturas, inscrições, grutas ou grupos de elementos com valor universal excepcional, do ponto de vista da história, da arte ou da ciência. Além de obras produzidas pelo homem, ou obras conjugadas do homem e da natureza, integram a categoria de Patrimônio Natural monumentos naturais, formações geológicas e fisiográficas "e as zonas estritamente delimitadas que constituem habitat de espécies animais e vegetais ameaçadas, com valor universal excepcional do ponto de vista da ciência ou da conservação" (UNESCO, 1972).

Esses critérios, no entanto, não deram conta da diversidade do patrimônio mundial, e foi criada a classificação de Sítio Misto. São considerados «património misto cultural e natural», os bens que respondem a uma parte ou à totalidade das definições de património cultural e natural, conforme especifica o art. 46 das Orientações Técnicas para Aplicação da Convenção do Patrimônio Mundial (versão 2012). 
No Brasil, estão inscritos como Patrimônio da Humanidade, no critério de Paisagem Natural, os bens: Parque Nacional do Iguaçu; Mata Atlântica: Reservas do Sudeste; Parque Nacional Serra da Capivara; Costa do Descobrimento: Reservas da Mata Atlântica; Área de Conservação do Cerrado; Área de Conservação do Pantanal; Parque Nacional do Jaú; e llhas Atlânticas Brasileiras: Fernando de Noronha e Atol das Rocas (site da Unesco).

Atualmente, a classificação de Patrimônio Natural tem sido discutida e questionada. Para alguns estudiosos, todo patrimônio é cultural, inexistindo o que tem sido denominado de natural, principalmente por dois motivos: um deles é que não haveria lugar algum do planeta em que o homem não tivesse tocado, e o outro é de que o próprio olhar e a classificação que se faz de algo como natural é, em si, uma prática cultural. Partindo deste princípio, toda paisagem passível de valoração patrimonial seria, a priori, uma paisagem cultural.

É no contexto das demandas e ampliações dos conceitos de paisagens culturais urbanas que a cidade do Rio de Janeiro foi inscrita na Lista de Patrimônio da Humanidade, reunindo aspectos naturais, como as montanhas e a orla marítima da Baía de Guanabara, e aquelas paisagens culturais intencionalmente concebidas pelo homem, como a Floresta da Tijuca, o Jardim Botânico, o Passeio Público, o Aterro do Flamengo e a orla de Copacabana.

O Dossiê da candidatura do Rio de Janeiro, apresentado integralmente em inglês, considerou que paisagens culturais urbanas se caracterizam pela complexidade de elementos naturais e antropológicos. No caso do Rio de Janeiro, a diversidade do sítio natural em que a cidade cresceu teria produzido uma variedade de paisagens culturais, em que a relação entre a montanha e o mar foi fator preponderante. A cidade e as sociabilidades foram constituídas entre estes dois elementos naturais, conformando e conformada por eles, em tempos históricos distintos, como descrito no fragmento abaixo, constante do Dossiê apresentado à Unesco.

Passeio Público Square and Flamengo Park are examples of city parks constructed at different historic times (the first was constructed in the 18th century and the second in the 20th century) but with the same objective: to enhance the quality of the environment and provide access to the views of the Guanabara Bay landmarks. (DOSSIÊ RJ, p. 28) 
A arquiteta Márcia Batista escreveu que o sítio proposto como Rio Paisagem Cultural contém áreas exemplares da cidade, reunidas em dois setores articulados entre si pela malha urbana, com suas cadeias montanhosas constituindo a zona de amortecimento. $\mathrm{O}$ primeiro setor é formado pelo Parque Nacional da Tijuca, Parque Lage e Jardim Botânico. O outro, pela sucessão dos elementos litorâneos - Parque do Flamengo com o Museu de Arte Moderna e áreas adjacentes (Passeio Público, Praça Paris, Outeiro da Glória); bem como a entrada da Baía da Guanabara, com seus morros e fortalezas dos lados leste e oeste (Rio e Niterói), estendendo-se até a enseada de Botafogo. Ainda faz parte desta segunda área, a praia de Copacabana com suas extremidades: morro do Leme e forte de Copacabana, estendendo-se à pedra do Arpoador (BATISTA, 2011:2).

Este recorte, com base no texto do Dossiê, foi definido para incluir os mais importantes exemplos da diversidade geomorfológica e ecológica da cidade, com a qual o homem construiu uma interação especial e onde a relação entre a montanha e o mar é mais forte. Contudo, entre as variadas paisagens culturais conformadas entre a montanha e o mar, as favelas foram excluídas da área inscrita.

Em correspondência enviada por Regina Durighello, diretora do Programa de Patrimônio Mundial, Icomos, datada de 6 de dezembro de 2011, foi solicitado que se considerasse a possibilidade de estender a área proposta, para incluir na delimitação o Morro do Cantagalo, Morro dos Cabritos, Morro da Saudade, Morro de São João e Morro da Babilônia, bem como as colinas acima e ao redor da Comunidade do Vidigal.

Em resposta à correspondência, assinada por Luiz Fernando de Almeida, presidente do IPHAN, em março de 2012, foi justificada a não inclusão das áreas propostas:

Morro do Vidigal, Dois Irmãos Park, and Leblon neighborhood - these areas are the product of more recent urbanization, specifically the 1940s, and, as such, to do not contribute to protecting the historical, environmental, or aesthetic value of the proposed Site. Therefore, we have decided back in 2009, not to include this area within the Site or its Buffer Zone. The history of the initial stages of the city's urbanization and the creation of the cultural corridor relating to the beaches and Atlantic ocean is contained in Component 4, where Copacabana beach became a paradigm of the beach city and of carioca culture, serving as an inspiration for the arts, literature, and music that extols the outstanding universal value of the Site. The hills behind Copacabana to the edge of the Rodrigo de Freitas Lagoon - we reiterate the limits of the proposed Site as laid out in the 
candidacy document. We do not advocate inclusion of these areas, because the components 1, 2, 3 , and 4 contain all of the attributes for preservation of the outstanding universal values justified in the candidacy document. The hills are important elements of environmental interconnection in the Buffer Zone, where they do not represent universal values, but, instead, protect and underscore the values of the four components of the proposed Site. (DOSSIÊ RJ, p. 487)

Os responsáveis pelo Dossiê optaram por uma resposta que justificasse o recorte, sem entrar no mérito da não inclusão dos morros referenciados e da ocupação de alguns deles por favelas e comunidades.

As cidades de Buenos Aires (Argentina) e de Paraty (RJ), para citar dois exemplos recentes e próximos, também se inscreveram para engrossar a mesma Lista, e ambas tiveram as candidaturas iniciais recusadas pela Unesco. O próprio Rio de Janeiro, em 2002, também teve uma candidatura recusada para Sítio Misto. A campanha "Buenos Aires Paisaje Cultural de la Humanidad" foi amplamente divulgada em 2006 e teve quatro temas chave: "El Río, la Pampa, la Barranca histórica y la inmigración" (DOSSIÊ Buenos Aires, 2005). Aspectos naturais aliados à ocupação humana fizeram da diversidade cultural o carro chefe da candidatura de Buenos Aires. Na 32 a sessão da Unesco, realizada em Quebec, no Canadá, em 2008, os membros da Comissão decidiram pela não inscrição de Buenos Aires à Lista com a alegação de "critérios culturais".

Paraty apresentou Dossiê intitulado "O Caminho do Ouro e sua paisagem". O julgamento da inscrição ocorreu em 2009, na $33^{\circ}$ Conferência da Unesco, realizada em Sevilha, na Espanha. Um dos aspectos da negativa foi que o Dossiê apresentado oferecia "ênfase forte no centro histórico e falta de uma maior ênfase na paisagem". Para a Unesco, o Brasil possui significativos bens inscritos na categoria de Centro Histórico, e o objetivo da inscrição nas atuais Listas de Patrimônio da Humanidade seria a representatividade e não a exaustão de um mesmo tema. Na reunião, foi julgado o adiamento da consideração para uma reformulação mais abrangente como Sítio Misto, destacando o seu excepcional valor natural e cultural. Paraty ainda não apresentou novo Dossiê.

Com o tema da preservação das paisagens culturais em voga, o intuito deste texto é realizar uma reflexão a respeito da prática da preservação desta tipologia de bens no âmbito do órgão federal - atual IPHAN, no século XX e início do XXI. Entre a década de 
1930 e de 2000, houve uma mudança significativa no tratamento ao tema paisagem cultural.

Para esta exposição, arrolamos como fonte a Revista do Patrimônio, publicada desde 1937, assim como os bens inscritos no Livro de Tombo Arqueológico, Etnográfico e Paisagístico. Ao comparar um e outro, é possível perceber que havia uma conexão estreita entre as publicações do periódico oficial e a prática efetiva de tombamentos.

A historiadora Márcia Chuva escreveu que o investimento feito pelo SPHAN, nos anos iniciais [1937-1945], foi no sentido de construir uma arte brasileira que se enquadrasse nos padrões universais. O resultado foi, propriamente, a invenção do barroco brasileiro (CHUVA, 2009: 259). As chaves da arte e de um lugar histórico, que não era outro senão o passado colonial, com sua arquitetura religiosa, administrativa e civil das classes abastadas, foram as bandeiras sob as quais comungaram, durante décadas, os técnicos e dirigentes do órgão de preservação federal.

Seria possível utilizar a chave das identidades culturais brasileiras aplicada à categoria de paisagem cultural? Quais seriam, nos dias atuais, os critérios para a eleição de uma paisagem cultural representativa dessas identidades brasileiras? O silêncio quanto à existência das favelas na paisagem urbana do Rio de Janeiro, no Dossiê de candidatura entregue à Unesco, e a própria eleição da cidade carioca podem sinalizar algumas indicações.

Referenciado nas normativas e nas publicações da SPHAN desde a década de 1930, o termo paisagem, ainda sem a adjetivação de paisagem cultural, apresentava-se como figurativo e não se enquadrava na valoração preservacionista dos primeiros tempos do órgão federal. Fato que norteia esta assertiva é o pouco uso que se fez do Livro de Tombo Arqueológico, Etnográfico e Paisagístico até a década de 1970.

Vozes como a da zoóloga paulista Bertha Lutz tentaram incluir, na pauta das ações de salvaguarda, a preservação dos monumentos e riquezas naturais. Em 1933, representando o Museu Nacional do Rio de Janeiro, Bertha Lutz propôs um Projeto, na VII Conferência Internacional Pan-Americana, realizada em Montevidéu. De acordo com Maria Tarcila Ferreira Guedes, foi naquela Conferência que a temática da preservação 
cultural adquiriu a maior importância até então atribuída ao assunto pelos países membros. Dentre as questões referentes à preservação, discutidas durante a Conferência de 1933, uma delas teria sido a proposta de Bertha Lutz para inclusão dos "monumentos e riquezas naturais" nos tratados a serem discutidos durante a Conferência (GUEDES, 2011: 08).

A Revista do Patrimônio, ainda hoje em circulação, é fonte privilegiada para compreender como a questão da paisagem foi tratada nesse momento que é considerado a "fase heróica do SPHAN" (FONSECA, 2005:82). Márcia Chuva escreveu que, durante o período ditatorial da Era Vargas, foram estabelecidos todos os vetores de consolidação do que seria patrimônio nacional. Nesse período, teria sido definido o que deveria ser patrimônio cultural brasileiro, e foram lançadas as bases do SPHAN, determinando as diretrizes dos anos posteriores, principalmente até a década de 1970, quando houve uma mudança significativa nos direcionamentos preservacionistas, marcados pela renovação dos quadros de pessoal da instituição (CHUVA, 2009:260). Nesse período, o recorte patrimonial cuidadosamente construído seria também naturalizado. Portanto, em consonância com o pensamento desta autora, é significativo percorrer os primeiros tempos do SPHAN na busca desta construção da ideia de patrimônio no Brasil, com foco no tratamento dado ao tema da paisagem cultural.

Na Revista $n^{\circ} 1$ do SPHAN, publicada em 1937, há uma matéria intitulada: "A natureza e os monumentos culturais", assinada pelo naturalista e geógrafo Raimundo Lopes (18941941). O artigo tinha sido apresentado originalmente em 1934, na $1^{\text {a }}$ Conferência Brasileira de Proteção à Natureza, organizada no Rio de Janeiro pela Sociedade dos Amigos das Árvores, com apoio e infraestrutura do Museu Nacional e patrocínio de Getúlio Vargas (FRANCO, 2002:79).

José Luiz de Andrade Franco, dissertando sobre a Conferência, escreveu que havia um grupo razoavelmente organizado, constituído em sua maioria por cientistas, intelectuais e funcionários públicos integrantes da Sociedade dos Amigos das Árvores. Este grupo pretendia garantir que fossem implementadas pelo Estado políticas relacionadas à conservação do patrimônio natural brasileiro (FRANCO, 2002:78). Para ele, o relativo sucesso desse grupo esteve associado ao fato de ter relacionado suas preocupações com a proteção da natureza, com a questão da identidade nacional, uma vez que, por sua 
riqueza, diversidade e beleza, proporcionava o estabelecimento de laços afetivos entre o indivíduo e o seu solo natal (FRANCO, 2002:78:89).

A identidade nacional, como é de conhecimento comum, foi o pano de fundo sobre o qual foram finamente trançadas as práticas e políticas preservacionistas do SPHAN. No entanto, parece-nos, a questão da proteção aos monumentos naturais distanciou-se desse ideário de identidade nacional, dentro das valorações patrimoniais dirigidas pelo órgão federal, a partir de 1937. E ficou restrita, durante muitas décadas, ao Código Florestal Brasileiro (1932 e 1965) e aos órgãos diretamente ligados à proteção das florestas, das águas e dos recursos naturais como um todo. Como correntes separadas, sem elos de ligação.

Na palestra de abertura da $1^{\text {a }}$ Conferência, Leôncio Correia, presidente da Sociedade dos Amigos das Árvores, discorreu sobre: "o culto e proteção, a defesa do patrimônio florestal, escopo supremo da nossa Sociedade, representa a parte básica do grande problema que se impõe modernamente ao mundo civilizado sob a fórmula da Proteção à Natureza". Ele afirmou que o problema transcendente abrangia não só a proteção da flora e da fauna, como, também, como complemento e consequência, a proteção das paisagens e o resguardo dos sítios pitorescos (in: FRANCO, 2002:80).

O conferencista citou o que se fazia a respeito do culto e proteção à natureza nos Estados Unidos e na Itália. Certamente, ele era conhecedor dos estudos de Carl Sauer e dos geógrafos da Escola de Berkeley, assim como das ações efetivadas no norte da América, para criação de Parques Nacionais, desde 1872 (Yellowstone), motivadas pelas descobertas da biologia e por uma filosofia inspirada no romantismo (FRANCO, 2002:82). José Luiz Franco acredita que, naquele momento, a ideia de paisagismo aparecia, também, com frequência, reforçando a perspectiva de uma "natureza jardim" (FRANCO, 2002:86). Ou seja, uma natureza recriada e moldada com os valores estéticos do homem.

Foi neste ambiente da Conferência, que Raimundo Lopes apresentou o seu texto e, três anos mais tarde, o publicaria no primeiro número da Revista do SPHAN. Lopes enfatizou a relação existente entre natureza e cultura: "protege-se a natureza para bem da cultura; e a recíproca é verdadeira: o amparo aos monumentos da cultura reverte em proteção à natureza" (LOPES, 1937:78). Para José Luiz Franco, esta percepção de Lopes 
relacionava-se com a ideia oriunda do Romantismo, de que a nacionalidade era fruto da convergência entre a história de um povo e o ambiente natural (FRANCO, 2002:91).

No número inaugural da Revista do Patrimônio, escreveram, também, Rodrigo Melo Franco de Andrade, Afonso Taunay, Heloísa Alberto Torres, Lúcio Costa, Gilberto Freyre, Francisco Marques dos Santos, Roquette Pinto, Paulo Barreto, Godofredo Filho, Aníbal Fernandes, Mário de Andrade, Nuto Sant'Anna, Noronha Santos e Epaminondas de Macedo. Em sua pesquisa com a publicação, Márcia Chuva observou que a relação entre natureza e patrimônio cultural era uma temática inusitada para a época [1937-1945], que foi tratada num único artigo - de Raimundo Lopes, e na Revista de número 1, que se propunha a abordar uma ampla diversidade temática, e que não seria repetida com tanta intensidade posteriormente (CHUVA, 2009:269).

$\mathrm{Na}$ realidade, a temática natureza e patrimônio cultural era inusitada dentro das discussões patrimoniais selecionadas pelo grupo de intelectuais modernistas de 1937, que dirigiu o SPHAN. Como citado, havia movimentos neste sentido ocorrendo em âmbito internacional, principalmente nos Estados Unidos, e articulados por pessoas e/ou grupos no Brasil, como exemplifica o Projeto proposto por Bertha Lutz, na VII Conferência Internacional Pan-Americana, de 1933. Bem como a ocorrência da $1^{\text {a }}$ Conferência Brasileira de Proteção à Natureza, no Rio de Janeiro, que fazia coro com os Congressos Internacionais para a Proteção à Natureza, realizados em Paris, em 1923 e 1931.

Reforçando o quadro, em 1943 foi fundada a UICN - União Internacional para a Conservação da Natureza, em Glanz, Suíça, composta por mais de mil organizações (BERJMAN, 2011:3). Uma escolha precisava ser feita, para constituição da identidade nacional brasileira e de passado histórico a serem valorados e representados na proteção aos monumentos culturais, e, certamente, paisagem e natureza não foram os escolhidos naquele momento.

Um segundo e último artigo foi escrito por Raimundo Lopes, na Revista do Patrimônio de número 2, de 1938, intitulado "Pesquisa etnológica sobre a pesca brasileira no Maranhão". Neste artigo, ele versa sobre as diversidades de técnicas de pesca no estado do Maranhão, em que ainda se podiam notar traços remanescentes de elementos 
africanos e portugueses. O falecimento, em 1941, aos 47 anos, colocou fim às suas pesquisas e atribuições no Conselho Consultivo do SPHAN.

Outra fonte arrolada para esta análise foi o Livro do Tombo Arqueológico, Etnográfico e Paisagístico, instituído pelo Decreto-Lei 25/1937, no Capítulo II - Do Tombamento. A análise dos bens inscritos neste Livro de Tombo, ao longo do tempo, oferece-nos indicações da prática de preservação das paisagens culturais no Brasil. O Decreto-Lei assim referenciou este Livro de Tombo: "as coisas pertencentes às categorias de arte arqueológica, etnográfica, ameríndia e popular, e bem assim as mencionadas no $\S 2^{\circ}$ do citado art. 10" (DECRETO-LEI 25/1937).

O parágrafo mencionado considera:

$\S 2^{\circ}$ Equiparam-se aos bens a que se refere o presente artigo e são também sujeitos a tombamento os monumentos naturais, bem como os sítios e paisagens que importe conservar e proteger pela feição notável com que tenham sido dotados pela natureza ou agenciados pela indústria humana. (DECRETO-LEI 25/1937) (grifo nosso)

Contudo, apesar da criação do Livro de Tombo Arqueológico, Etnográfico e Paisagístico, e de o Decreto-Lei 25/1937 não deixar margem de dúvida quanto à tipologia de bens que deveriam ser tombados e inscritos nesse Livro, o que se verifica é que sua utilização foi restrita, principalmente no que tange aos bens referenciados no $\S 2^{\circ}$.

Para melhor visualização dos bens inscritos nesse Livro, apresentamos um quadro com a relação dos tombamentos que se enquadram na categoria daqueles do $\S 2^{\circ}$ do DecretoLei 25/1937 e das conceituações de patrimônio natural, patrimônio cultural e paisagem cultural da Unesco. As datas limites de inscrição dos bens referenciados abaixo são 1938 e 2009, estão organizados por ordem crescente de data de inscrição.

\begin{tabular}{|c|c|l|c|c|c|}
\hline & Ano & \multicolumn{1}{|c|}{ Bem } & $\begin{array}{c}\text { Inscrição } \\
\text { número }\end{array}$ & Localização & No Processo \\
\hline 1 & 1938 & Jardim Botânico* & 2 & $\begin{array}{c}\text { Rio de Janeiro - } \\
\text { RJ }\end{array}$ & 0157-T-38 \\
\hline 2 & 1938 & $\begin{array}{l}\text { llha da Boa Viagem: conjunto arquitetônico e } \\
\text { paisagístico }\end{array}$ & 3 & Niterói - RJ & 0164-T-38 \\
\hline 3 & 1940 & Jardim do Hospital São João de Deus & 9 & $\begin{array}{c}\text { São João de } \\
\text { Deus - BA }\end{array}$ & 0202-T-39 \\
\hline 4 & 1956 & $\begin{array}{l}\text { Conjunto arquitetônico e paisagístico do Santuário } \\
\text { de Nossa Senhora da Piedade }\end{array}$ & 16 & Caeté - MG & 0526-T-55 \\
\hline
\end{tabular}




\begin{tabular}{|c|c|c|c|c|c|}
\hline 5 & 1960 & Serra do Curral: conjunto paisagístico & $29-\mathrm{A}$ & $\begin{array}{c}\text { Belo Horizonte - } \\
\text { MG }\end{array}$ & 0591-T-58 \\
\hline 6 & 1962 & Lapa da Cerca Grande (Gruta da Lapinha) & 30 & $\begin{array}{c}\text { Matozinhos - } \\
\text { MG }\end{array}$ & 0491-T-53 \\
\hline 7 & 1962 & Gruta de Mangabeira & $32-\mathrm{A}$ & Ituaçu - BA & 0606-T-60 \\
\hline 8 & 1965 & Parque à Rua Marechal Deodoro, 365 & 37 & Joinville - SC & 0754-T-65 \\
\hline 9 & 1965 & Área do Passeio Público, antiga Praça dos Mártires & 38 & Fortaleza - CE & 0744-T-64 \\
\hline 10 & 1965 & Aterro do Flamengo & 39 & $\begin{array}{c}\text { Rio de Janeiro - } \\
\text { RJ }\end{array}$ & 0748-T-64 \\
\hline 11 & 1965 & Parque Nacional da Tijuca e floresta & 42 & $\begin{array}{c}\text { Rio de Janeiro - } \\
\text { RJ }\end{array}$ & 0762-T-65 \\
\hline 12 & 1970 & Fazenda Santa Eufrásia: casa, bosque e parque & 48 & Vassouras - RJ & 0789-T-67 \\
\hline 13 & 1973 & Morro do Pão de Açúcar & 52 & $\begin{array}{c}\text { Rio de Janeiro - } \\
\text { RJ }\end{array}$ & 0869-T-73 \\
\hline 14 & 1973 & Morro da Urca & 53 & $\begin{array}{c}\text { Rio de Janeiro - } \\
\text { RJ }\end{array}$ & 0869-T-73 \\
\hline 15 & 1973 & Morro da Babilônia & 54 & $\begin{array}{c}\text { Rio de Janeiro - } \\
\text { RJ }\end{array}$ & 0869-T-73 \\
\hline 16 & 1973 & Corcovado / Penhasco Corcovado & 55 & $\begin{array}{c}\text { Rio de Janeiro - } \\
\text { RJ }\end{array}$ & 0869-T-73 \\
\hline 17 & 1973 & Morro Dois Irmãos / Penhasco Dois Irmãos & 56 & $\begin{array}{c}\text { Rio de Janeiro - } \\
\text { RJ }\end{array}$ & 0869-T-73 \\
\hline 18 & 1973 & Pedra da Gávea & 57 & $\begin{array}{c}\text { Rio de Janeiro - } \\
\text { RJ }\end{array}$ & 0869-T-73 \\
\hline 19 & 1973 & Morro Cara de Cão & 58 & $\begin{array}{c}\text { Rio de Janeiro - } \\
\text { RJ }\end{array}$ & 0869-T-73 \\
\hline 20 & 1973 & $\begin{array}{l}\text { Horto Florestal: conjunto paisagístico / conjunto } \\
\text { arquitetônico }\end{array}$ & 61 & $\begin{array}{c}\text { Rio de Janeiro - } \\
\text { RJ }\end{array}$ & 0633-T-61 \\
\hline 21 & 1978 & $\begin{array}{l}\text { Grutas do Lago Azul e de Nossa Senhora } \\
\text { Aparecida }\end{array}$ & 74 & Bonito - MS & 0979-T-78 \\
\hline 22 & 1983 & $\begin{array}{l}\text { Serra do Monte Santo, BA: conjunto arquitetônico, } \\
\text { urbanístico, natural e paisagístico }\end{array}$ & 85 & $\begin{array}{l}\text { Monte Santo - } \\
\text { BA }\end{array}$ & 1060-T-82 \\
\hline 23 & 1984 & Açude do Cedro & 87 & Quixadá, CE & \\
\hline 24 & 1986 & Serra da Barriga & 90 & $\begin{array}{c}\text { União dos } \\
\text { Palmares - AL }\end{array}$ & 1069-T-82 \\
\hline 25 & 1993 & Parque Nacional da Serra da Capivara & 108 & $\begin{array}{l}\text { São Raimundo } \\
\text { Nonato, PI }\end{array}$ & 1322-T-92 \\
\hline 26 & 1994 & $\begin{array}{l}\text { Parque Zoobotânico do Museu Paraense Emílio } \\
\text { Goeldi }\end{array}$ & 110 & Belém, PA & $1297-\mathrm{T}-89$ \\
\hline 27 & 1997 & Pampulha: conjunto arquitetônico e paisagístico & 115 & $\begin{array}{c}\text { Belo Horizonte - } \\
\text { MG }\end{array}$ & $1341-\mathrm{T}-94$ \\
\hline 28 & 2000 & $\begin{array}{l}\text { Morro do Pai Inácio: conjunto paisagístico e Rio } \\
\text { Mucugezinho }\end{array}$ & 120 & \begin{tabular}{|c|} 
Parque \\
Nacional da \\
Chapada \\
Diamantina - \\
Palmeiras - BA \\
\end{tabular} & $1356-\mathrm{T}-95$ \\
\hline 29 & 2000 & Lagoa Rodrigo de Freitas: conjunto paisagístico & 121 & $\begin{array}{c}\text { Rio de Janeiro - } \\
\text { RJ }\end{array}$ & 0878-T-73 \\
\hline 30 & 2001 & Ilha do Campeche: sítio arqueológico e paisagístico & 126 & $\begin{array}{c}\text { Florianópolis - } \\
\text { SC }\end{array}$ & 1426-T-98 \\
\hline 31 & 2003 & $\begin{array}{l}\text { Sítio Roberto Burle Marx e sua coleção } \\
\text { museológica e bibliográfica }\end{array}$ & 129 & $\begin{array}{c}\text { Rio de Janeiro - } \\
\text { RJ }\end{array}$ & 1131-T-84 \\
\hline 32 & 2004 & Dedo de Deus, maciço rochoso & 130 & Guapimirim - RJ & 1405-T-97 \\
\hline
\end{tabular}




\begin{tabular}{|l|l|l|c|l|l|}
\hline 33 & 2008 & Conjunto paisagístico Serra dos Serrotes & 144 & Quixadá - CE & 1377-T-1996 \\
\hline
\end{tabular}

QUADRO 1 - Bens paisagísticos tombados pelo IPHAN entre 1938 e 2009

* Bens inclusos no recorte do Dossiê para inscrição do Rio de Janeiro na Lista da Unesco, na categoria Paisagem Cultural. Fonte: IPHAN/COPEDOC. 2009.

Não foram incluídos neste quadro os conjuntos urbanos, históricos e paisagísticos, os museus e coleções etnográficas, os terreiros de candomblé, o Porto de Manaus, as ruínas, entre outros que não se enquadravam na categoria "paisagístico" aqui discriminada. Foram inscritos, ainda, no Livro Arqueológico, Etnográfico e Paisagístico, entre 1938 e 2009, 54 conjuntos urbanos, nos mais diversos estados do Brasil. Considerando que, apenas em Salvador, os tombamentos urbanos foram divididos em 11 partes diferenciadas, temos 44 quatro cidades brasileiras com conjuntos urbanos, históricos e paisagísticos inscritos nesse Livro de Tombo.

A inscrição de número 1 é do acervo do Museu da Magia Negra ou Museu da Polícia Civil, localizado na cidade do Rio de Janeiro, inscrito em 05/05/1938, Processo de tombamento 0035-T-38. A inscrição deste bem no Livro Arqueológico, Etnográfico e Paisagístico referese ao patrimônio etnográfico, por este motivo, não foi referenciado no quadro acima.

O gráfico abaixo mostra a curva crescente de tombamentos de bens paisagísticos, entre os anos de 1938 e 2009, referentes apenas àqueles listados no Quadro 1. 


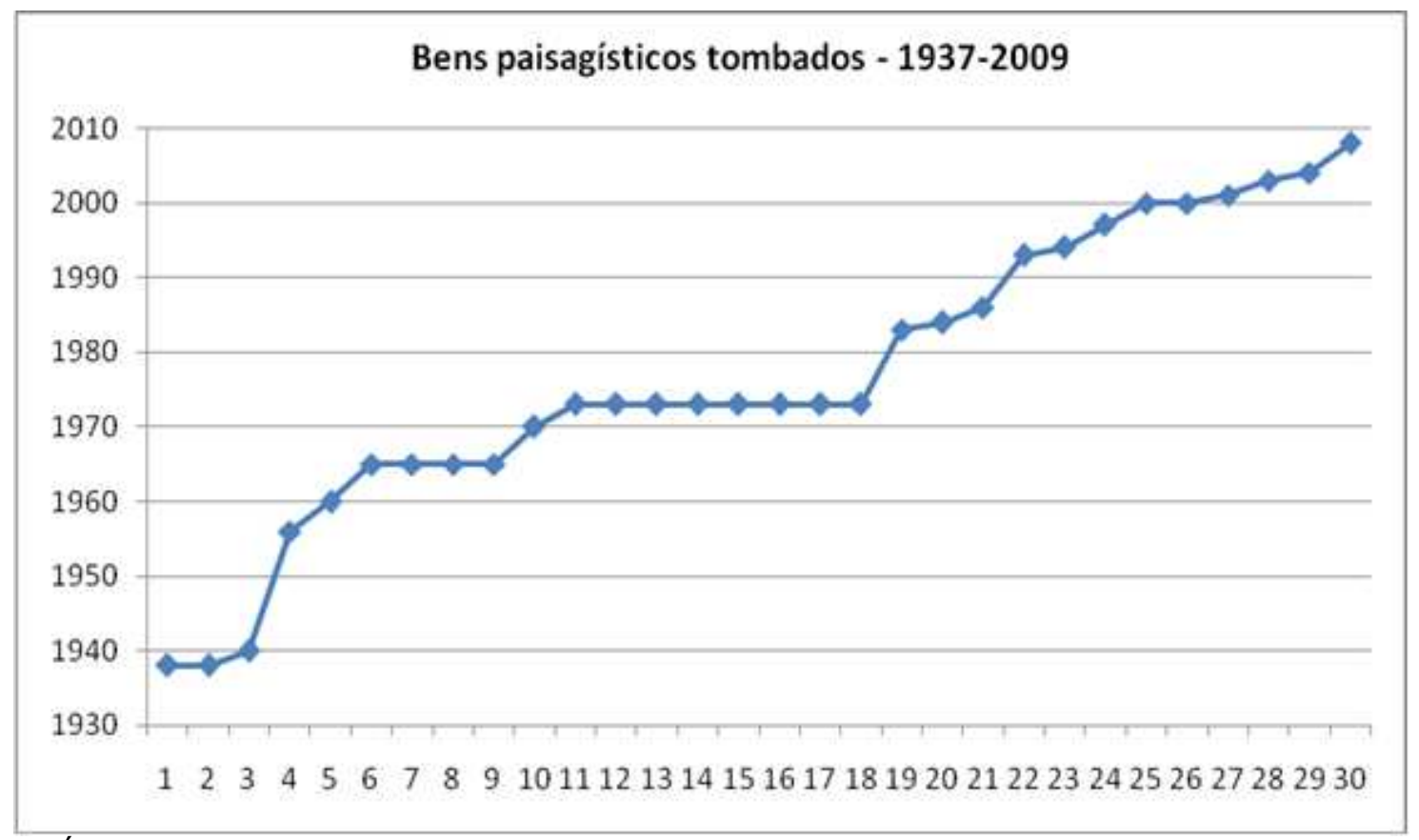

GRÁFICO 1 - Bens paisagísticos tombados no Brasil entre 1937 e 2009. Fonte: Gráfico elaborado a partir dos dados levantados em: IPHAN/COPEDOC. 2009.

Observa-se que, entre as décadas de 1930 e de 1950, apenas quatro bens da categoria paisagístico foram tombados. O pico dos tombamentos ocorreu entre as décadas de 1960 e 1970, principalmente nesta última, com nove bens inscritos. Contribuiu para esta ascensão, em grande parte, os bens naturais tombados no Rio de Janeiro, tais como o Morro do Pão de Açúcar, o Morro da Urca, o Morro da Babilônia, o Corcovado / Penhasco Corcovado, o Morro Dois Irmãos / Penhasco Dois Irmãos, a Pedra da Gávea, o Morro Cara de Cão e Horto Florestal com seu conjunto paisagístico e arquitetônico. A inscrição destes bens no Livro de Tombo, em 1973, faz eco à Conferência da Unesco de 1972, referenciada no início deste texto.

Dos 33 bens listados no quadro, treze estão localizados na cidade do Rio de Janeiro, e mais três, no estado do RJ, o que significa que $53,3 \%$ dos bens paisagísticos tombados pelo IPHAN, no período relacionado, estão concentrados no estado do Rio de Janeiro.

Para a Unesco, as paisagens culturais dividem-se em três categorias principais: a intencionalmente concebida e criada pelo homem, como jardins e parques; a paisagem essencialmente evolutiva; e as paisagens associativas. Analisando os bens protegidos no Brasil pelo IPHAN identificados na primeira categoria de paisagem cultural, ou seja, os jardins e parques tombados isoladamente, independente do Livro de Tombo a que foram inscritos, dos dez salvaguardados, oito estão localizados na cidade do Rio de Janeiro: 
1. Passeio Público do Rio de Janeiro, data do tombamento: $30 / 06 / 1938$, inscrito no Livro Histórico e Livro das Belas Artes.

2. Jardim e Morro do Valongo - RJ, data do tombamento: 30/06/1938, Livro Histórico e Livro das Belas Artes.

3. Jardim Botânico do Rio de Janeiro, data do tombamento: 30/05/1938, Livro Arqueológico, Etnográfico e Paisagístico.

4. Campo de Santana / Praça da República, tombado em 30/06/1938 e destombado, posteriormente, pelo presidente Getúlio Vargas, em 1943, para construção da Avenida Presidente Vargas, no Rio de Janeiro.

5. Parque da Quinta da Boa Vista, data do tombamento: 30/06/1938, Livro das Belas Artes e Livro Histórico.

6. Jardim do Hospital São João de Deus - BA, data do tombamento: 09/07/1940, Livro Arqueológico, Etnográfico e Paisagístico.

7. Parque Lage, data do tombamento: 14/06/1957, Livro Histórico.

8. Passeio Público, no município de Fortaleza, estado do Ceará. (Fortaleza/CE

). Data do tombamento: 13/04/1965, Livro Arqueológico, Etnográfico e Paisagístico.

9. Floresta da Tijuca. Data do tombamento: 27/04/1967. Livro Arqueológico, Etnográfico e Paisagístico.

10. Sítio de Roberto Burle Marx, data do tombamento: 04/08/2003, Livro Arqueológico, Etnográfico e Paisagístico.

Além destes jardins tombados isoladamente, há, na cidade carioca, significativos jardins tombados em conjunto com a edificação:

1. Jardins da Casa de Grandjean de Montigny, data do tombamento: 10/08/1938, Livro de Belas Artes.

2. Jardins do Palácio do Catete, data do tombamento: 06/04/1938, Livro Histórico, Livro das Belas Artes.

3. Jardins da Casa de Rui Barbosa, tombamento em 11/05/1938, Livro de Belas Artes e Livro Histórico.

4. Jardins de Burle Marx no Palácio Gustavo Capanema, no Rio de Janeiro, data de tombamento: 18/03/1948. Livro de Belas Artes. 
5. Parque Brigadeiro Eduardo Gomes (Parque do Aterro do Flamengo - RJ). Tombamento municipal (Lei Municipal 2.287 de 04/01/1995, DOM, 06/01/1995) e tombamento federal (Processo 748-T-64, data do tombamento: 28/07/1965, Arqueológico, Etnográfico e Paisagístico).

Estes dados nos remetem ao tema abordado na abertura deste texto, sobre a identificação de uma identidade brasileira a partir da categoria de paisagem cultural. Analisando todos os dados expostos, parece-nos que a ideia de que alguns elementos da paisagem da cidade do Rio de Janeiro poderiam ser identificados como representativos de uma paisagem cultural brasileira tem sido gestada há algumas décadas. Desta forma, a cidade não teria sido escolhida ao acaso, fruto de abordagens recentes, para sua inscrição na categoria de Paisagem Cultural na lista da Unesco.

Ainda com base na visualização do Gráfico 1, vê-se que, a partir da década de 1980, a quantidade de bens tombados e inscritos no Livro de Tombo Arqueológico, Etnográfico e Paisagístico aumentou significativamente. Comparando os tombamentos às publicações na Revista do Patrimônio, chegaremos à edição de número 19, datada de 1984, designada de "relançamento".

Depois de quatro anos de interrupção de circulação, a Revista voltava a circular mantendo o "compromisso fundamental com a pesquisa e o debate, firmado por Rodrigo M. F. de Andrade, o fundador do SPHAN, ao apresentar, em 1937, a edição de estreia" (REVISTA do Patrimônio, 1984:3). Curiosamente, foi nesta edição que a questão da preservação dos monumentos naturais esteve novamente em pauta, concomitantemente ao aumento no número de tombamentos de bens dessa categoria.

$\mathrm{Na}$ edição, três artigos foram publicados abordando a temática, numa sessão denominada: Ecologia e Governo, a saber: "Patrimônio Natural: utilitarismo versus ética ecológica”, de Ângela Tresinari Bernardes Quintão; "Pelo conhecimento amplo de nossos ecossistemas", de lêda Lúcia de Souza Carneiro da Paixão; "O tombamento na preservação de áreas naturais”, do arquiteto Antônio Luiz Dias de Andrade.

Em 1987, a Revista do Patrimônio n 22 tratou do tema mais intensamente, com a mesa redonda "Patrimônio Natural”, em que estiveram presentes Aziz Ab'Saber, Ibsen Câmara, 
José Lutzenberger, José Tabacow e William Rodrigues. Na mesma edição, foram publicados os artigos "A natureza no patrimônio cultural do Brasil", de Carlos Alberto Ribeiro de Xavier e "Ambiente e culturas: equilíbrio e ruptura no espaço geográfico ora chamado Brasil", de Aziz Ab'Saber.

A partir deste número e data, os assuntos relacionados aos monumentos naturais, a paisagem urbana, a fotografia de natureza etc. apareceram referenciados nos textos publicados da Revista, mesmo quando o tema principal do artigo não era esta tipologia de bens.

Com a exposição destes dados, outras questões somam-se àquela inicial, a respeito das chaves para a eleição de uma paisagem cultural representativa das identidades brasileiras. O que transforma, portanto, qualquer porção de um dado território em local especial e unívoco? O que torna este recorte uma paisagem merecedora de receber uma inscrição na lista da Unesco, ou um tombamento, ou, ainda, a Chancela da Paisagem Cultural Brasileira? O que faz, desta região e não daquela outra, espaço singular e excepcional? Quem escolhe, com qual motivação e para quais grupos, determinada paisagem?

Estas são questões que inquietam desde os primórdios das políticas públicas de salvaguarda do patrimônio cultural, e certamente não possuem respostas satisfatórias. Entretanto, colocando nestes termos, é possível igualar os métodos das políticas preservacionistas atuais, no que diz respeito à paisagem cultural, àqueles mesmos elementos que estiveram presentes nas décadas de 1930 e 1940, no Brasil, quando um grupo criou um ideário de identidade e de preservação para o país. Ou seja, o método não mudou, mudaram os personagens, as motivações e as diretrizes.

Os tombamentos de bens paisagísticos com critérios culturais, naturais ou associativos no Rio de Janeiro, pelo IPHAN, assim como a indicação da cidade carioca para a Lista de Patrimônio da Humanidade na categoria de paisagem cultural são indicativos dessas escolhas, pautadas pelos atores e diretrizes do tempo presente. Essas escolhas e valorações nos ajudam a compreender a lógica de eleição e de salvaguarda desta categoria de bens pelo órgão federal. 
Não há contestação da importância da salvaguarda de bens identificados como Paisagem Cultural no Brasil. Este intento figura-se, certamente, como um dos desafios das políticas preservacionistas do presente. É preciso cuidar, no entanto, para que não se celebre, novamente, um lugar e uma paisagem de valor excepcional, que daria conta das múltiplas diversidades culturais e paisagísticas brasileiras.

Para concluir, retornemos ao início desta exposição, à cidade alemã de Hildesheim e sua lendária roseira milenar. Conta-se que, durante um bombardeio da Segunda Guerra Mundial, em 1945, a igreja foi destruída, e a roseira quedou sob os escombros. De acordo com vídeo divulgado no site da Unesco, parecia impossível reconstruir a catedral destruída. Milagrosamente, ramos da roseira começaram a brotar debaixo das ruínas e a florir sobre elas. Esta foi a motivação para os fiéis reconstruírem a igreja medieval e a própria cidade devastada. Com a reconstrução da edificação, a roseira foi mantida na abside da catedral. Juntas permanecem, como um dos mais celebrados monumentos históricos do lugar e exemplo de como natureza e bens edificados podem conviver harmoniosamente.

\section{Referências bibliográficas}

BATISTA, Márcia Aguiar Nogueira. Candidatura do Rio de Janeiro a Patrimônio Mundial Categoria Paisagem Cultural. Anais do VII Seminário DOCOMOMO Brasil, 2009.

BERJMAN, Sônia. De los jardines históricos a los paisajes culturales: la labor de Icomos. In: II Seminário Arqueologia na Paisagem: um olhar sobre os jardins históricos. Caderno de Resumos. Rio de Janeiro: EBA / UFRJ, 2011.

BUENOS Aires Paisaje Cultural: el río, la pampa, la barranca histórica y la inmigración. Dossier de Elevación de La Candidatura de Buenos Aires al Comité de Patrimonio Mundial. Unesco. Ministerio de Cultura, Subsecretaria de Patrimonio Cultural. Diciembre de 2005.

CHUVA, Márcia Regina Romeiro. Os Arquitetos da Memória: Sociogênese das Práticas de Preservação do Patrimônio Cultural no Brasil (anos 1930-1940). 1. ed. Rio de Janeiro: Editora UFRJ, 2009. v. 1. 480 p.

DECRETO-LEI 25, de 30 de novembro de 1937. Organiza a proteção do Patrimônio Histórico e Artístico Nacional.

FONSECA, Maria Cecília Londres. O Patrimônio em Processo: Trajetória da Política Federal de Preservação no Brasil. Rio de Janeiro: Ed. da UFRJ, IPHAN, 2005.

FRANCO, José Luiz de Andrade. A primeira Conferência Brasileira de Proteção à Natureza e a questão da identidade nacional. In: Duarte, Regina Horta. Varia História $n^{\circ}$ 26: Dossiê História e Natureza. Janeiro, 2002. p. 77-96. 
GUEDES, Maria Tarcila F. A preservação no contexto pan-americano. In: XXVI Simpósio Nacional de História, 2011. Anais. São Paulo: ANPUH-SP, 2011. v. 1.

IPHAN. Dossiê de Candidatura do Rio de Janeiro à Lista de Patrimônio da Humanidade. Rio de Janeiro: paisagens cariocas entre a Montanha e o Mar. 2012.

IPHAN/COPEDOC. Bens Móveis e Imóveis Inscritos nos Livros do Tombo do Instituto do Patrimônio Histórico e Artístico Nacional (1938 - 2009). Quinta Edição - 2009. Revista e Atualizada. Rio de Janeiro: IPHAN/COPEDOC, 2009.

LOPES, Raimundo. A natureza e os monumentos naturais. In: Revista do SPHAN, vol. 1, 1937.

MENESES, Ulpiano Toledo Bezerra. A paisagem como fato cultural. In: YÁZIGI, Eduardo (org.). Turismo e paisagem. São Paulo: Contexto, 2002. p. 29-64.

BATISTA, Márcia Aguiar Nogueira. Candidatura do Rio de Janeiro a Patrimônio Mundial categoria Paisagem Cultural. Anais do VII Seminário DOCOMOMO Brasil, 2009.

REVISTA de Horticultura. Frederico de ALBUQUERQUE. No 6, de junho de 1876. Acervo Biblioteca Nacional.

REVISTA do Patrimônio Histórico e Artístico Nacional. Edições de 1937 a 2002. Publicações do IPHAN - Instituto do Patrimônio Histórico e Artístico Nacional.

SAUER, Carl Orwin. La morfologia del paisaje. 1925. In: Revista Polis. Revista Académica Universidad Bolivariana.

UNESCO. Dossiê: Carioca Landscapes between the Mountain and the Sea. Disponível em: http://whc.unesco.org/en/list/1100/documents/. Acesso em outubro de 2012.

UNESCO. Operational Guidelines for the Implementation of the World Heritage Convention. Versão 2011.

UNESCO. Orientações Técnicas para Aplicação da Convenção do Patrimônio Mundial. Versão 2012.

UNESCO. Vídeo documentário da Unesco sobre St Mary's Cathedral and St Michael's Church at Hildesheim. Disponível em: $<$ http://whc.unesco.org/en/list/187/video $>$. Acesso em outubro de 2012. s/d.

\section{Créditos}

* Doutoranda do Programa de Pós-Graduação em História da UNICAMP. Bolsista FAPESP. Mestre em História Social da Cultura pela UFMG - FAFICH (2006). E-mail: cristmag@gmail.com. 